\title{
"ACOSTÚMBRATE A PENSAR QUE LA MUERTE PARA NOSOTROS NO ES NADA" (EPICURO)... ¿¿O LO ES TODO?
}

Alfredo Ferrante

Universidad Alberto Hurtado

\section{1. $\mathrm{HeCHOS}^{1}$}

Un automóvil Fiat Punto entra en una carretera por el lado izquierdo y choca frontalmente con el vehículo Renault Espace. El conductor del primer coche pierde la vida de inmediato, pasando solo tres horas entre accidente y fallecimiento.

Padres y hermanas reclaman tanto daños patrimoniales como no patrimoniales al propietario del vehículo y a su compañía aseguradora ${ }^{2}$, presentándose en juicio solo la segunda.

Entre otras voces se reclaman los daños patrimoniales futuros y el daño no patrimonial (danno biologico), iure hereditatis, derivados de la muerte de su pariente.

La primera ${ }^{3}$ y segunda ${ }^{4}$ instancia deniegan ambas indemnizaciones, aunque conceden los daños no patrimoniales iure propio de los demandantes, si bien se identifica una responsabilidad conjunta con el perjudicado.

\footnotetext{
${ }^{1}$ Corte Suprema di Cassazione, Sezioni Unite Civili, $\mathrm{N}^{\mathrm{o}} 15350 / 15$, de 22 de julio.

${ }^{2}$ El coche, sin embargo, era conducido por otro sujeto, el hijo del propietario.

${ }^{3}$ Tribunale Cuneo de 1 de diciembre de 2003.

${ }^{4}$ Corte di Appello di Torino No ${ }^{4} 23 / 2007$, de 16 de marzo.
}

En primera instancia se consideran las partes concausantes del daño en una medida del 70\% y 30\%. Luego, en apelación, la responsabilidad del vehículo que provocó la muerte es aumentada a un $80 \% 0^{5}$. Se considera responsable, también, a la víctima, al conducir sin cinturón de seguridad y a una velocidad mayor de la convenida en un lugar fuera del centro habitado. Sin embargo, la apelación cambia los parámetros concausales al quedar demostrado, por prueba pericial, que, cuando el sujeto conducía a $120 \mathrm{~km} / \mathrm{h}$ -frente a una velocidad permitida de $90 \mathrm{~km} / \mathrm{h}$ - al ver al otro vehículo frenó de inmediato, reduciendo la velocidad a $103 \mathrm{~km} / \mathrm{h}$ al momento del impacto. Aún más, se considera que, incluso si la velocidad hubiera sido la regular $(90 \mathrm{~km} / \mathrm{h})$, no se hubiera podido evitar el choque, pero sí los efectos hubieran sido menores.

Se desestima el pago de una indemnización patrimonial por gastos futuros. Aunque los demandantes hayan probado que la víctima convivía

${ }^{5}$ Este aspecto es cuestión relativa a los hechos y por lo tanto no es revisable en casación. 
con los padres y que le otorgaba mil quinientos euros mensuales (aproximadamente $\$ 1.126 .000$ chilenos) no podía presumirse que el sujeto, de treinta y un años en el momento del fallecimiento, hubiera podido ingresar la misma cuantía (por lo menos) en el quinquenio siguiente. La Corte Suprema italiana estima que el razonamiento de la Corte de Apelaciones es correcto al haber supuesto que este importe fuera destinado para el propio mantenimiento del hijo, dado que nunca se ha probó por los recurrentes la insuficiencia económica de los padres.

De todos modos, la cuestión a resaltar es la denegación del daño biológico iure hereditatis. Es decir, el rechazo a la transmisibilidad de la acción por daños no patrimoniales a los herederos. La sentencia de la Corte Suprema italia186 na confirma la postura de los jueces anteriores.

\section{Marco y CONTEXTO DE REFERENCIA}

Debe destacarse la considerable importancia de este pronunciamiento, porque se redacta por la Corte Suprema en su Sezioni Unite, es decir, debe haberse autorizado previamente por el presidente de la Cassazione y puede darse solo si existen sentencias anteriores discordantes emitidas por el mismo órgano judicial. Algo parecido, mas no idéntico, mutatis mutandis a los recursos de unificación de doctrina de la Corte Suprema chilena.

En efecto, en febrero de 2014 la Corte Suprema en su sección civil (la sala $3^{\mathrm{a}}$ ) había operado un revirement respecto a la postura que denegaba la indemnización por daño iure hereditatis por muerte instantánea. La sentencia de la Cassazione No 1361/2014 ${ }^{6}$, adopta una solución favorable a la indemnización para esta clase de muerte, habiéndose dedicado en sus más de cien páginas a desmenuzar las problemáticas y a cambiar la tradicional tendencia afirmada ya bajo la vigencia del anterior Codice Civile ${ }^{7}$.

Por ello, la misma sala $3^{\text {a }}$, al conocer un mes después otro supuesto parecido y al observar este contraste, decide someter la cuestión al pleno, mediante la solicitud formulada en el mes de marzo del mismo año ${ }^{8}$ y cuya respuesta ha encontrado su manifestación pública en julio de 2015, aunque se haya llegado a ella mucho antes ${ }^{9}$.

El pronunciamiento vuelve a tomar la anterior postura que deniega la indemnización iure hereditatis por la muerte instantánea del sujeto y lo hace en el pleno, lo que evidentemente asume una cabal importancia y justifica estas líneas.

Antes de continuar, debe realizarse una aclaración importante. Los

${ }^{6}$ Cass. Civ., $3^{\text {a }}$, n. 1361/2014, de 3 de febrero, Danno e Responsabilità, 2014, p. 363 y ss, en Responsabilità civile e previdenza, 2014, p. 492 y ss., en Nuova Giurisprudenza Civile e Commentata, 2014, I, p. 396 y ss op. cit., 2014, II, p. 245 y ss, en Foro Italiano, 2014, I, columna 719 y ss. En todos estos se pueden encontrar los correspondientes comentarios a esta sentencia.

${ }^{7}$ Cass. Civ. Sezioni Uniten. 3475/1925, de 22 de diciembre, en Foro Italiano, 1926, I, columna 328, en Giurisprudenza Italiana, 1926, I, 1, p. 67.

${ }^{8}$ Cass. Civ. (Ordinanza) 2014,n. 5056/2014, de 4 marzo, en Danno e Responsabilità, 2014, p. 387, op. cit., p. 783.

${ }^{9}$ Efectivamente la doctrina observa como todo ha sido una suspense, dado que el Supremo Colegio celebró la audiencia conclusiva tres meses después de la solicitud, es decir, en fecha 17 de junio de 2014: Busnelli (2015), p. 1207. 
razonamientos del pronunciamiento no tratan de manera expresa ni cuestionan el daño no patrimonial (iure propio) de los familiares ni la indemnización iure hereditatis cuando el fallecido ha sobrevivido por un largo tiempo después del evento dañino.

Ambas voces se indemnizan en el ordenamiento italiano y es la misma sentencia, la que evidencia que son aspectos diferentes del tema tratado ${ }^{10}$.

Así, en el Derecho italiano sí que es posible indemnizar el daño de muerte iure hereditatis, si ha pasado un largo plazo entre la lesión y la muerte del perjudicado. La duda se manifiesta en caso de muerte instantánea, aspecto que la Corte Suprema italiana con su sentencia a Sezioni Unite excluye, a pesar de algunos pronunciamientos anteriores ${ }^{11}$ y de la reciente Cass. Civ. $\mathrm{N}^{\mathrm{O}} 1361 / 2014$, que en forma expresa toman una postura contraria.

Es precisa otra aclaración. Aquí hablaré en general de indemnización del daño no patrimonial, dado que el ordenamiento italiano asume importantes matices, no pudiéndose hablar exclusivamente de un daño moral por muerte.

${ }^{10}$ Observa claramente esta separación Franzoni (2015), p. 900.

${ }^{11}$ Estos derivan esencialmente de la jurisprudencia menor que en esta sede no procede analizar, y de otros procedimientos de la Cassazione. Destaca la presencia de sentencias previas de la Corte Suprema que se alejan de la orientación que sigue la Cass. 15359/2015: BUSNELLI (2015), p. 1207. Para la jurisprudencia menor v.gr. Tribunale Brindisi, causa civile No 242/2006, juez Antonio Ivan Natali disponible en www. leggioggi.it/wp-content/uploads/2011/03/ sentenza_Ostuni.pdf [fecha de consulta: $30 \mathrm{de}$ octubre de 2015].
Por ejemplo, la jurisprudencia ha intentado superar el rechazo a la indemnización en estos casos, mediante la creación de determinadas voces de daños. Al denegar la postura tradicional del llamado daño biológico terminal ${ }^{12}$, donde es relevante la duración de la supervivencia del sujeto, se ha venido hablando de una indemnización por un daño moral subjetivo o de un daño catastrofale, que justifica no desde el punto de vista de una lesión psicofísica, sino por la conciencia del deceso inminente, que produce sufrimiento y agonía en el sujeto antes de morir ${ }^{13}$. Por ello, se ha llegado a indemnizar de igual forma el daño, justificándolo desde otras perspectivas, sin que hayan diferencias sustanciales en relación con los importes de la indemnización ${ }^{14}$.

\section{VIDA y SAlUd}

Como presupuesto de partida, se asume que existe un derecho a la vida $y$ un derecho a la salud y a la integridad física, bienes jurídicos que son constitucionalmente tutelados (arts. 2 y 32 de la Constitución italiana ${ }^{15}$ y art. $19 \mathrm{~N}^{\circ} 1$ y No 9 de la Constitución Política chilena).

${ }^{12}$ Este se liquidaría mediante a la indemnización por una invalidez absoluta máxima temporánea del sujeto, más un daño moral en sus coeficientes máximos según las tablas predispuestas por el ordenamiento italiano en estos casos. Se reenvía también con referencias jurisprudenciales de ambas tipología de daños a Franzoni (2015), p. 900.

${ }^{13}$ Cfr. Dellacasa (2015), p. 1308.

${ }^{14}$ Cfr. Franzoni (2015), p. 900; Dellacasa (2015), p. 1309.

${ }^{15}$ V.gr. cfr. Carbone (2015), p. 897. 
Estos dos bienes pueden o no interaccionar entre sí, por ejemplo, vinculando la muerte al bien salud, como la evolución in peius de la integridad física lesionada. En este sentido, el fallecimiento se plantearía como su reflejo más importante, la mayor ofensa posible de este bien protegido.

No se estima así por el pleno de la Corte Suprema italiana, que separa estos dos aspectos no pudiéndose relacionar la muerte con el bien salud.

En este sentido, en el momento de su muerte, el sujeto ha cesado de existir y, por ende, no puede probar ningún perjuicio. En consecuencia, si la víctima no puede adquirir el crédito resarcitorio, tampoco puede transmitirlo a los herederos.

La Corte Suprema se pronuncia no solo sobre la falta de legitimación 188 activa por parte de los herederos sino, también, sobre la imposibilidad de adquirir un verdadero derecho por parte del fallecido. Por ello, el bien vida debe ser protegido solamente durante su existencia y hasta su cese, afirmándose que:

"la muerte, por lo tanto, no representa la máxima ofensa posible del diferente bien 'salud', perjudicado por la lesión que ha generado la muerte".

La Corte resucita el argumento epicúreo expresado en la carta a $\mathrm{Me}^{-}$ ceneo, por la cual se expresaba que hay que ser feliz, ya que la muerte no puede temerse:

“el más estremecedor de los males, la muerte, no es nada para nosotros, ya que mien- tras nosotros somos, la muerte no está presente y cuando la muerte está presente, entonces nosotros no somos. No existe, pues, ni para los vivos ni para los muertos, pues para aquéllos todavía no es, y éstos ya no son".

La Corte Suprema afirma que, escindiéndose la tutela del derecho a la integridad física, de la tutela de la muerte, solo son indemnizables las lesiones procedentes de la primera, es decir, el daño que es consecuencia del hecho generador. En este sentido, el Tribunal desmonta el argumento que la Cass. No 1316/2014, favorable a la indemnización del daño iure hereditatis por muerte, había ofrecido. Esta última, aun cuando asumía que, en términos generales, el daño indemnizable era aquel que es consecuencia del evento, presenta una excepción en el caso de daño por muerte: la excepción justifica indemnizar no solo las consecuencias del evento sino que el evento mismo que se produce, es decir, la muerte en sí.

La justificación de la sentencia de 2014 mueve sus pasos desde una conciencia social más amplia, dado que la muerte es un suceso que vale para todos: en este sentido, debe ser el evento de excepción que debe indemnizarse. De lo contrario, se lesionaría el derecho primario a la vida. Las Sezioni Unite, en cambio, rechazan este argumento diciendo que, por sí, la indemnización iure propio de los familiares ya es motivo suficiente. Pero aquí el razonamiento cae al identificar necesariamente el estatus de familiar 
con el de heredero. De hecho, carece de fundamentación lo sostenido:

"pretender otorgar una tutela indemnizatoria también al difunto corresponde (...) solamente al contingente objetivo de hacer lograr más dinero a los conjuntos".

\section{4. ¿COMPENSACIÓN O SANCIÓN?}

La justificación principal que mueve el razonamiento del pleno italiano, es la función compensatoria de la responsabilidad civil, denegando su perspectiva sancionadora.

Como premisa se destaca que la función totalmente reparadora no puede lograrse en el daño no patrimonial. Aun más, dado que esta última no se ha elevado a principio fundamental por el Tribunal Constitucional italiano, por lo que es compatible con la exclusión de un crédito indemnizatorio ${ }^{16}$.

No obstante, esta premisa es un "error no justificable" del Tribunal, dado que no hay un automatismo entre esta afirmación y la otra, que limitaría de manera ilegítima el derecho de los herederos ${ }^{17}$.

Se combate el papel sancionador de la responsabilidad civil bajo la

${ }^{16}$ La Corte Suprema se apoya sobre algunas sentencias de la Corte Costituzionale: Corte Cost. No 132 del 1985, en Foro Padano, 1985, I, p. 57 y ss, Corte Cost. No 369/1996, de 2 de noviembre, en Foro Italiano, 1997, I, columna 2401; Corte Cost. No $158 / 1999$ en Giurisprudenza costituzionale, 1999, p. 1173 y ss.

${ }^{17}$ Como se destaca, esto presupondría que la indemnización por muerte instantánea viene subestimada respecto de la indemnización por lesión Ponzanelli (2015), p. 910. constatación de que es este el que ha fundamentado la indemnización del daño iure hereditatis por la sentencia $\mathrm{N}^{\mathrm{o}} 1316 / 2014$, sentencia que ha justificado que el pronunciamiento deba realizarse por el pleno del tribunal.

La argumentación para desmontar esta función es doble.

Un primer razonamiento se realiza marcando la neta separación entre Derecho Penal y Derecho Privado, afirmando que la función enunciada contraviene el orden público y con ello, también, intrínsecamente, el ordenamiento:

"la progresiva autonomía de la disciplina de la responsabilidad civil de la penal ha conllevado a la obliteración de la función sancionadora y de disuasión”.

Pese a que la reflexión de la Corte se fundan en premisas de anteriores pronunciamientos ${ }^{18}$, estos quedan mermados por la reciente apertura que otra sala de la Corte Suprema italiana -la sala primera (y no la tercera)hace a favor de los daños punitivos, aunque en su concepción de astreinte, y de su admisión favorable al orden público ${ }^{19}$. Esta nueva orientación no

${ }^{18}$ Cass. Civ. No ${ }^{\circ} 1183 / 2007$, de 19 de enero, en Foro Italiano, 2007, I; columna 1460 y ss, en Corriere Giuridico, 2007, n. 4, p. 497 y ss.; Cass. Civ. $\mathrm{N}^{\circ} 1781 / 2012$ de 8 de febrero, en Foto Italiano, 2012, I, columna 1449, en Danno e Responsabilità, 2012, p. 609 y ss; cfr. PALADINI (2015) p. 887.

${ }_{19}$ Cass. Civ. N ${ }^{\circ} 7613 / 2015$, de 15 de abril en www.cortedicassazione.it [fecha de consulta: 30 de octubre de 2015], que reconoce la conformidad del orden público de la sentencia de un juez belga que contiene un as- 
puede pasar desapercibida, aun cuando la doctrina la considera como una nueva tendencia que

"une dotes de responsabilidad cultura la una corajosa abertura hacia el futuro" ${ }^{20}$.

Así que, incluso si se considera que la función sancionatoria requeriría una tipificación de los supuestos fácticos admisibles y que en parte ya existen en el Derecho italiano ${ }^{21}$, lo que es cierto es que existe una tendencia hacia desvanecimiento de su negación $^{22}$.

Un segundo argumento de la Cassazione mueve siempre de la relación entre Derecho Privado y Penal. La Corte Suprema quiere desmontar el argumento originario formulado por 190 la doctrina italiana ${ }^{23}$ y luego hecho manifiestamente suyo por la de otros ordenamientos $^{24}$, según el cual es más conveniente matar que lesionar. Se considera que dicha argumentación es: "de indudable eficacia retórica", aunque "en realidad sea sólo sugestiva".

La Cassazione lo motiva por la presencia, en caso de muerte, de la sanción penal, aspecto que es más grave y que por lo mismo, tutela el derecho a la vida de mayor manera res-

treinte como función sancionatoria en caso de incumplimiento: cfr. PALAdini (2015), p. 887.

${ }^{20}$ Así Busnelli (2015), p. 1215.

${ }^{21}$ Se reenvía a la doctrina para algunas tipologías tipificadas: FrANZONI (2015), p. 903.

${ }^{22}$ Cfr. Busnelli (2015), pp. 1210-1211.

${ }^{23}$ Cfr. Giannini (1992), p. 603.

${ }^{24} \mathrm{Da}$ una muestra de esta internacionalización: Busnelli (2015), n. 4 p. 1207. pecto al bien salud ${ }^{25}$. En este sentido, la finalidad de disuasión se entrega al Derecho Penal. No obstante, el argumento propugnado por el pleno se debilita, no solo porque no ha sido desarrollado de manera pertinente y por eso se ha redactado de manera "apresurada ${ }^{26 "}$, sino porque no tiene en consideración un doble factor ${ }^{27}$. Por un lado, la argumentación del pleno se resiente cuando se constata que, penalmente el autor de un homicidio culposo viene expuesto a una condena levemente más grave de la que procede en caso de lesiones culposas. Por otro lado, el argumento del tribunal da lugar a una chispa que no enciende, cuando se trata de supuestos fácticos donde el sujeto no es imputable penal, pero sí civilmente.

\section{Mucha CARretera POR DElante}

La solución del pleno de la Cassazione claramente ha tomado partido en relación con la denegación de la concesión iure hereditatis del daño por muerte instantánea (y no en caso de supervivencia prolongada). No obstante, el recorrido es todavía muy largo. Y lo es no solo en Italia, donde la solución que se ha adoptado es criticable y en parte incoherente por las razones ya mencionadas ${ }^{28}$, sino,

${ }^{25}$ Cfr. Franzoni (2015), p. 903.

${ }^{26}$ Esta es la expresión de Busnelli (2015), n. 4 p. 1206.

${ }^{27}$ Como observan agudamente PARDOLESI \& Simone (2015), p. 908.

${ }^{28}$ Francesco BusNELLI críticamente considera que la Cassazione, de manera expedita se limita a enjaular los argumentos, sellando deliberadamente, mediante afirmaciones 
también, desde la óptica chilena. $\mathrm{Mu}$ chos e interesantes son los puntos de inspiración para un debate que debe y puede, necesariamente (re)abrirse en Chile y que queda de momento durmiente como carbón bajo una ceniza, listo para volverse a prender. Pero esta es otra historia.

\section{Bibliografía CITADA}

Busnelli, Francesco Donato (2015), "Tanto tuonò, che ... non piovve. Le Sezioni Unite sigillano il "sistema", in Corriere Giuridico, No 10. Milano.

Dellacasa, Matteo (2015), "Rinnovamento e restaurazione nel risarcimento del danno da morte", in $R i$ vista di Diritto Civile, No 5 . Padova.

Carbone, Vincenzo (2015), "Valori Personali ed economici della vita umana", in Danno e Responsabilità, $\mathrm{N}^{\mathrm{O}}$ 10. Milano.

Franzoni, Massimo (2015), "Danno tanatologico, meglio di no", in Danno e Responsabilità, $\mathrm{N}^{\mathrm{o}}$ 10. Milano.

Giannini, Gennaro (1992), "La risarcibilità del danno biologico in ipotesi di lesioni mortali", in Responsabilità civile e previdenza. $\mathrm{N}^{\circ} 5$. Milano.

Paladini, Mauro (2015), "Linee guida, buone pratiche e quantificazione del daño nella c.d. legge Balduzzi”, in Danno e Responsabilità, No 10 . Milano.

categóricas, el tema: BusNELLI (2015), pp. 12081209. En definitiva, se considera que quiere considerarse la impostación tradicional cuando, parafraseando el cuento de Melville, sería "preferible no hacerlo" Pardolesi \& Simone (2015), p. 907.
Pardolesi Roberto, Simone Roberto (2015), "Danno da Morte e stare decisis: la versione di Bartleby", in Danno e Responsabilità, $\mathrm{N}^{\circ} 10$. Milano.

Ponzanelli, Giulio (2015), "Le Sezioni Unite sul sanno Tanatologico", in Danno e Responsabilità, $\mathrm{N}^{\circ}$ 10. Milano.

\section{Sentencias CitadAS}

\section{A. Corte Suprema italiana}

Cass. Civ. Sezioni Uniten. 3475/1925, de 22 de diciembre, en Foro Italiano, 1926, I, columna 328, en Giurisprudenza Italiana, 1926, I, 1, p. 67 y ss.

Cass. Civ. n. 1183/2007, de 19 de enero, en Foro Italiano, 2007, I; columna 1460 y ss, en Corriere Giuridico, 2007, n. 4 , p. 497 y ss.

Cass. Civ. n. 1781/2012 de 8 de febrero, en Foto Italiano, 2012, I, columna 1449, en Danno e Responsabilità, 2012, p. 609 y ss.

Cass. Civ., $3^{\mathrm{a}}$, n. 1361/2014, de 3 de febrero, Danno e Responsabilità, 2014, p. 363 y ss, en Responsabilità civile e previdenza, 2014, p. 492 y ss, en Nuova Giurisprudenza Civile e Commentata, 2014, I, p. 396 y ss. op. cit., 2014, II, p. 245 y ss, en Foro Italiano, 2014, I, columna 719 y ss.

Cass. Civ. (Ordinanza) 2014, n. 5056/ 2014, de 4 marzo, en Corriere Giuridico, n. 10, 2015, p. 1203 y ss, en Danno e Responsabilità, No 10 , Milano, 2015 , p. 889 y ss.

Cass. Civ., 1a , n. 7613/2015, de 15 de abril disponible en www.cortedicassazione.it [fecha de consulta: 30 de octubre de 2015]. 
Cass. Civ. Sezioni Unite, n. 15350/15, de 22 de julio, en Danno e Responsabilità, $\mathrm{N}^{\mathrm{O}}$ 10. Milano.

\section{B. Tribunal Constitucional italiano}

Corte Cost. No 132 del 1985, en Foro Padano, 1985, i, p. 57 y ss.

Corte Cost. No 369/1996, de 2 de noviembre, en Foro Italiano, 1997, I, columna 2401.

Corte Cost. No 158/1999 en Giurisprudenza costituzionale, 1999, p. 1173 y ss.

\section{Jurisprudencia menor italiana}

Corte di Appello di Torino n. 423/2007, de 16 de marzo (inédita).

Tribunale Cuneo de 1 de diciembre de 2003 (inédita).

Tribunale Brindisi, causa civile No 242/ 2006, Juez Antonio Ivan Natali, disponible en www.leggioggi.it/wpcontent/uploads/2011/03/sentenza_Ostuni.pdf [fecha de consulta: 30 de octubre de 2015]. 